\title{
IMPROVEMENT OF DISSOLUTION RATE OF INDOMETHACIN FROM FAST DISSOLVING TABLETS
}

\author{
GITAM Institute of \\ Pharmacy, GITAM \\ University, Gandhi Nagar \\ Campus, Rushikunda, \\ Visakhapatnam-530045, \\ Andhra Pradesh, India
}

Submitted: $18-01-2014$

Revised: 02-02-2014

Accepted: 16-06-2014

*Corresponding author

Rabinarayan Parhi

Email :

bhu_rabi@rediffmail.com

\author{
Rabinarayan Parhi*, Nishant Reddy
}

\begin{abstract}
In the current study Indomethacin (IM) fast dissolving tablets (FDTs) were prepared by direct compression technique in order to enhance its dissolution rate. The tablets were formulated using two different approaches; super-disintegration and effervescence. A combination formulation of above approaches was also developed to further improve its properties. The super-disintegrants used in the formulae were sodium starch glycolate (Primogel), cross-povidone (Kollidon) and cross-carmellose (Ac-di-sol). Sodium bicarbonate and citric acid combination was employed as effervescent ingredients. The prepared powder mixtures of IM were subjected to evaluation of various pre-compression parameters and tablets were evaluated for weight variation, dimension, hardness, friability, drug content, disintegration, wetting time, uniformity of dispersion, in vitro drug release and stability studies. The FT-IR spectra shown there are no interaction between of IM with excipient. The results of pre-compression studies indicate acceptable flow property for all the powder mixtures. The data of weight variation, dimension, hardness, friability, uniformity of dispersion and drug content studies were within the official limits. The wetting time and disintegration time decreases considerably with the increase in super-disintegrants amount. By using the combination approach, the disintegration and wetting time further decreased. In vitro dissolution studies were carried out using phosphate buffer pH 6.8 as dissolution medium for $60 \mathrm{~min}$ and observed that formulation IF9, among superdisintegration approach, released highest percentage (97.13 \pm 2.09$)$ of IM. In vitro drug release was highest $(98.54 \pm 2.89)$ at $60 \mathrm{~min}$ for formulation IF11, when all the formulations were taken into consideration. The stability study was performed on the promised formulation IF11 at $40 \pm 2^{\circ} \mathrm{C} / 75 \pm 5 \%$ RH for 3 months and the results indicated that there were no significant changes in aforesaid tablet properties.
\end{abstract}

Key words: Fast dissolving tablet, Indomethacin, Super-disintegration, Effervescence.

\section{INTRODUCTION}

Oral drug delivery is the most widely used route of drug administration among all the routes that have been explored for the systemic delivery via various pharmaceutical products of different dosage forms (Ghosh et al., 2005) because of its distinct advantages of ease of administration, improved patient compliance, flexibility in designing the dosage form, least sterility requirements and avoidance of pain compared to parenteral route (Krishnaiah et al., 2002, Saurabh et al., 2011, Prabhu et al., 2011, Bhalla et al., 2012). Tablets and capsules are the most popular solid dosage forms administered orally. It is estimated that $50 \%$ of the population is affected by dysphasia (difficulty in swallowing), which is the major limitation associated with solid dosage forms such as tablet (Barnhart et al., 2007). In addition, it may pose problem for pediatric and geriatric patients who find swallowing difficult and for the treatment of some patients when water is not available in the case of motion sickness (kinetosis) and sudden attack of coughing during the common cold and bronchitis (Gryczke et al., 2011, Tritthart et al., 2001). This can be resolved by the preparation of rapidly dispersing or dissolving oral forms that combines both the properties of liquid and tablet dosage forms (Habibh et al., 2000). 
Dissolution Rate of Indomethacin

The orally disintegrating tablets are also called as orodispersible tablets (ODTs), quick disintegrating tablets, fast disintegrating tablets, fast dissolving tablets. United States Food and Drug Administration (US FDA) defined ODTs as "a solid dosage form containing medicinal substances or active ingredient which disintegrates rapidly usually within a matter of seconds when placed upon the tongue". US FDA further defines ODTs as solid oral preparations that disintegrate rapidly in the oral cavity with an in-vitro disintegration time of approximately $30 \mathrm{~s}$ or less (Guidance for industry, 2008). In addition, ODTs should have an acceptable taste and very short disintegration time, generally from few seconds to about a minutes, in the mouth. It is always a challenge to prepare ODTs having short oral disintegration time as it is with positive correlation with the mechanical strength of the tablets (Szakonyi et al., 2013).

Indomethacin belongs to non-steroidal anti-inflammatory drug class, which is used to reduce fever, pain and inflammation associated with musculo-skeletal and joint disorders including ankylosing spondolysis, rheumatoid arthritis, osteoarthitis and acute gout (Shen, 1982, Kulmacz, 1989, Nunchanit et al., 2013). It is described as Class II (poorly aqueous solubility and high permeability) drug in BCS. So, it is proposed to develop ODT dosage form of indomethacin to increase its solubility and subsequently bioavailability.

In the present investigation FDTs of IM were prepared by direct compression method using two approaches namely; superdisintegration and effervescence. The physicochemical properties of the particular disintegrants determine the disintegration mechanism followed by the disintegration time (Douroumis, 2007). The super-disintegrants used were Primogel, Kollidon and Ac-di-sol. In case of effervescence approach, sodium bicarbonate and citric acid were incorporated in tablet formulation as effervescent ingredients. Various powder mixtures underwent various pre-compression tests such as FT-IR studies, bulk and tapped density, angle of repose, Carr's index and Hausner ratio. The prepared tablets were evaluated for various physical parameters and in-vitro disintegration and dissolution tests.

\section{MATERIAL AND METHODS}

Indomethacin, Cross-carmellose sodium (Ac-di-sol), Cross-povidone (Kollidon) and Aerosil were suppied by Yarrow Chem Products, Mumbai. Lactose monohydrate, mannitol, menthol, magnesium stearate and sodium saccharin obtained from LOBA Chemie PVt. Ltd., Mumbai. Sodium starch glycolate (Primogel) and microcrystalline cellulose (Avicel PH101) were purchased from $\mathrm{CDH}$, New Delhi. All other chemicals used throughout the research were of analytical grades.

\section{Preparation of tablets}

Fast dissolving tablets of IM were prepared by direct compression technique using two different approaches such as superdisintegration and effervescence and also a formulation containing their combination. The formulae for all batches are represented in table I. Indomethacin dose was $150 \mathrm{mg}$ and the total weight of tablet was fixed at $350 \mathrm{mg}$. Avicel PH102 and mannitol were used as directly compressible material and diluent, respectively. Mentioned quantities of drug and other ingredients were weighed accurately and passed through mesh no \# 60 before mixing. All the above ingredients were transferred to mortar and mixed thoroughly for 15 minutes except magnesium stearate, which was added and mixed for $5 \mathrm{~min}$ before compression by spatulation method. The above powder mixture were compressed into tablets using ten station minipress punching machine (Rimek Compression Machine) equipped with flatefaced $9.0 \mathrm{~mm}$ punch. For tablets prepared by effervescent technique, sodium bicarbonate and citric acid were accurately weighed and preheated to $80^{\circ} \mathrm{C}$ to obtain a constant weight before mixing with other ingredients (Kadria et al., 2013).

\section{Drug-Excipient Interaction Study}

Drug-excipient interaction study was carried out by FT-IR technique (FTIR-1700, Shimadzu, Kyoto, Japan) in order to determine the interaction of IM with the excipient used in the formulations. The pure drug and the physical mixture (1:1) of drug with MCC, Primogel, Kollidon and Ac-di-sol were scanned in $\mathrm{KBr}$ discs in the range of $4000-400 \mathrm{~cm}^{-1}$. 
Rabinarayan Parhi

Table I. Formulation of fast dissolving tablets of Indomethacin

\begin{tabular}{|c|c|c|c|c|c|c|c|c|c|c|c|}
\hline $\begin{array}{l}\text { Formulation/ } \\
\text { Ingredients }\end{array}$ & IF1 & IF2 & IF3 & IF4 & IF5 & IF6 & IF7 & IF8 & IF9 & IF10 & IF11 \\
\hline Indomethacin & 150 & 150 & 150 & 150 & 150 & 150 & 150 & 150 & 150 & 150 & 150 \\
\hline MCC & 120 & 120 & 120 & 120 & 120 & 120 & 120 & 120 & 120 & 120 & 120 \\
\hline Mannitol & 53 & 59 & 45 & 53 & 59 & 45 & 53 & 59 & 45 & 12 & --- \\
\hline Primogel & 4 & 8 & 12 & ---- & ---- & --- & --- & --- & ---- & --- & --- \\
\hline Kollidon & ---- & --- & ---- & 4 & 8 & 12 & ---- & ---- & --- & --- & --- \\
\hline Ac-di-sol & --- & --- & ---- & --- & ---- & --- & 4 & 8 & 12 & --- & 12 \\
\hline $\begin{array}{c}\text { Sodium } \\
\text { bicarbonate }\end{array}$ & --- & --- & ---- & --- & --- & --- & --- & --- & --- & 25 & 25 \\
\hline Citric acid & --- & --- & --- & --- & --- & --- & --- & --- & --- & 20 & 20 \\
\hline Aerosil & 4 & 4 & 4 & 4 & 4 & 4 & 4 & 4 & 4 & 4 & 4 \\
\hline Sod. saccharin & 10 & 10 & 10 & 10 & 10 & 10 & 10 & 10 & 10 & 10 & 10 \\
\hline Mag. stearate & 4 & 4 & 4 & 4 & 4 & 4 & 4 & 4 & 4 & 4 & 4 \\
\hline Menthol & 5 & 5 & 5 & 5 & 5 & 5 & 5 & 5 & 5 & 5 & 5 \\
\hline
\end{tabular}

* Total weight of tablet $=350 \mathrm{mg}$

\section{Micromeritics study}

Bulk density and Tapped density

Bulk density determined by filling fixed amount (10gm) of powder blends into a volumetric flask $(50 \mathrm{~mL})$ followed by recording its volume. Tapped density was determined in a graduated measuring cylinder after subjecting to 100 taps fixed over a digital tapped density apparatus (Electrolab-ETP-1020) (Peppas et al., 1985).

\section{Angle of repose}

Angle of repose of powder blends were measured by fixed height cone method or funnel method. The height of the funnel was adjusted in such a way that the tip of the funnel just touched the tip of the heap of the powder blends $(4 \mathrm{~cm})$. Accurately weight amount of powder mixtures were taken in the above funnel and allowed to flow through the funnel freely. The height and radius were measured and the angle of repose were calculated (Cooper et al., 1986)

\section{Carr's index and Hausner ratio}

Compressibility index and Hausner ratio for all powder blends were determined by following equations (Wells, 2002)

Carr's index $(\%)=\underset{\text { TBD }}{\text { TBD-LBD }} \quad 100 \%$
Hausner ratio $(\%)=\frac{\text { TBD }}{\text { LBD }} 100 \%$

Post-compression parameters (Goto et al., 2004, Wu et al., 2009)

Dimension

Thickness and diameter were measured for five tablets by using Vernier calipers and the average was expressed in $\mathrm{mm}$.

\section{Weight uniformity}

Twenty tablets were weighed individually using electronic balance (Shimadzu CorporationBL-220H) and then the average tablet weight was calculated. The percentage variation of each tablet from the average tablet weight was determined.

\section{Hardness}

Hardness was determined by randomly taking 10 tablets from each batch, using Monsanto hardness tester (Electrolab Pvt. Ltd., India) and the average diametric compression force $\left(\mathrm{Kg} / \mathrm{cm}^{2}\right)$ to crush the tablets were determined.

Friability

The friability of a sample of 10 tablets was measured using Roche friabilator (Electro lab, EF-2, Mumbai, India). The weight of 10 tablets was recorded and was placed in drum of a Roche Friabilator, which was run at $25 \mathrm{rpm}$ 
Dissolution Rate of Indomethacin

for 4min. Tablets were reweighed after dedusting and the percentage of friability was determined.

\section{Disintegration}

Disintegration test was carried out by using disintegration apparatus (ED-2L Electrolab). One tablet was placed in each of the six tubes of the basket assembly and was dipped in phosphate buffer $\mathrm{pH} 6.8$ maintained at $37 \pm 1^{\circ} \mathrm{C}$. The time in seconds taken for complete disintegration of tablets were recorded.

\section{Drug content}

Five tablets were taken and crushed in mortar. From this the amount of powder equivalent to $25 \mathrm{mg}$ of IM was transferred in to a conical flask containing $25 \mathrm{ml}$ of methanol. The absorbance was measured at $320 \mathrm{~nm}$ after suitable dilution.

\section{Wetting time and Water absorption ratio}

The method used a piece of tissue paper folded twice was placed in a petri dish with a $10 \mathrm{~cm}$ diameter containing $10 \mathrm{ml}$ of phosphate buffer $\mathrm{pH}$ 6.8. A tablet was placed on the tissue paper and the time required for complete wetting was recorded (Tejvir et al., 2011). Three trials for each batch were performed. Water absorption ratio was calculated employing following equation;

$$
\mathrm{WA}=\frac{(\mathbf{W a}-\mathbf{W b})}{\mathbf{W b}} \times \mathbf{1 0 0}
$$

Where, Wa and $\mathrm{Wb}$ are the weight after and before water absorption, respectively

\section{Dispersion}

Uniformity of dispersion was performed to determine the dispersion of the drug in the water uniformly. Two tablets were placed in $100 \mathrm{~mL}$ of water in a $250 \mathrm{~mL}$ beaker and were stirred uniformly for a minute and then the solution was passes through the $710 \mu \mathrm{m}$ mesh or sieve no 22 \# see that whether all the contents of the mixture pass through the sieve without leaving a residue on the mesh (Indian Pharmacopeia, 2010).

\section{In-vitro dissolution studies}

Dissolution test for prepared FDTs of IM were performed using USP type II apparatus (Electrolab TDT-08L, Mumbai).
Phosphate buffer pH $6.8(900 \mathrm{ml})$ maintain at $37 \pm 0.5^{\circ} \mathrm{C}$ was used as dissolution medium and the rotational speed of paddle was kept at 50 $\mathrm{rpm}$. Five milliliter of aliquots were withdrawn at 5, 10, 15, 30 and $60 \mathrm{~min}$ and replaced with fresh dissolution media maintained at same temperature. The samples were passed through membrane filter (pore size, $0.45 \mu \mathrm{m}$ ) and assayed immediately for IM content by UV spectrophotometer at 320nm (UV-1800, Shimadzu, Japan). This test was performed on 6 tablets and mean \pm SD calculated.

\section{Statistical analysis}

One way analysis of variance (One-way ANOVA) with student Newman Keuls multiple comparison tests was used to perform statistical significant differences between various in vitro drug release data at 95\% confidential level (5\% significance level). It was carried out employing 30 days trial version of GraphPad Instat software.

\section{Stability studies}

Short-term stability study was performed on the promising formulation (IF11) for a period of 3 months at accelerated condition $(40 \circ \pm 2 \circ \mathrm{C} / 75 \pm 5 \% \mathrm{RH})$. Fixed number of tablets (25) were packed in amber colored rubber stoppered vials and placed in stability chamber (JRIC 11, Osworld, Mumbai) maintained at above condition. At intervals of 1 month, the tablets were visually examined for any physical changes; changes in drug content and at the end of three months, tablets were withdrawn and evaluated for in vitro drug release (Swamy et al., 2011).

\section{RESULT AND DISCUSSIONS}

Fast dissolving tablets of IM were prepared by direct compression technique, which is said to be most simple, less time consuming and economical. Two approaches such as super-disintegration and effervescence were employed for fast dissolving of tablets. Mannitol was incorporated into tablet formulation for multiple purposes such as cooling effect due to negative heat of solution, non-hygroscopic, good aqueous solubility and pleasant feeling in the mouth (Banker et al., 1987). 
Rabinarayan Parhi

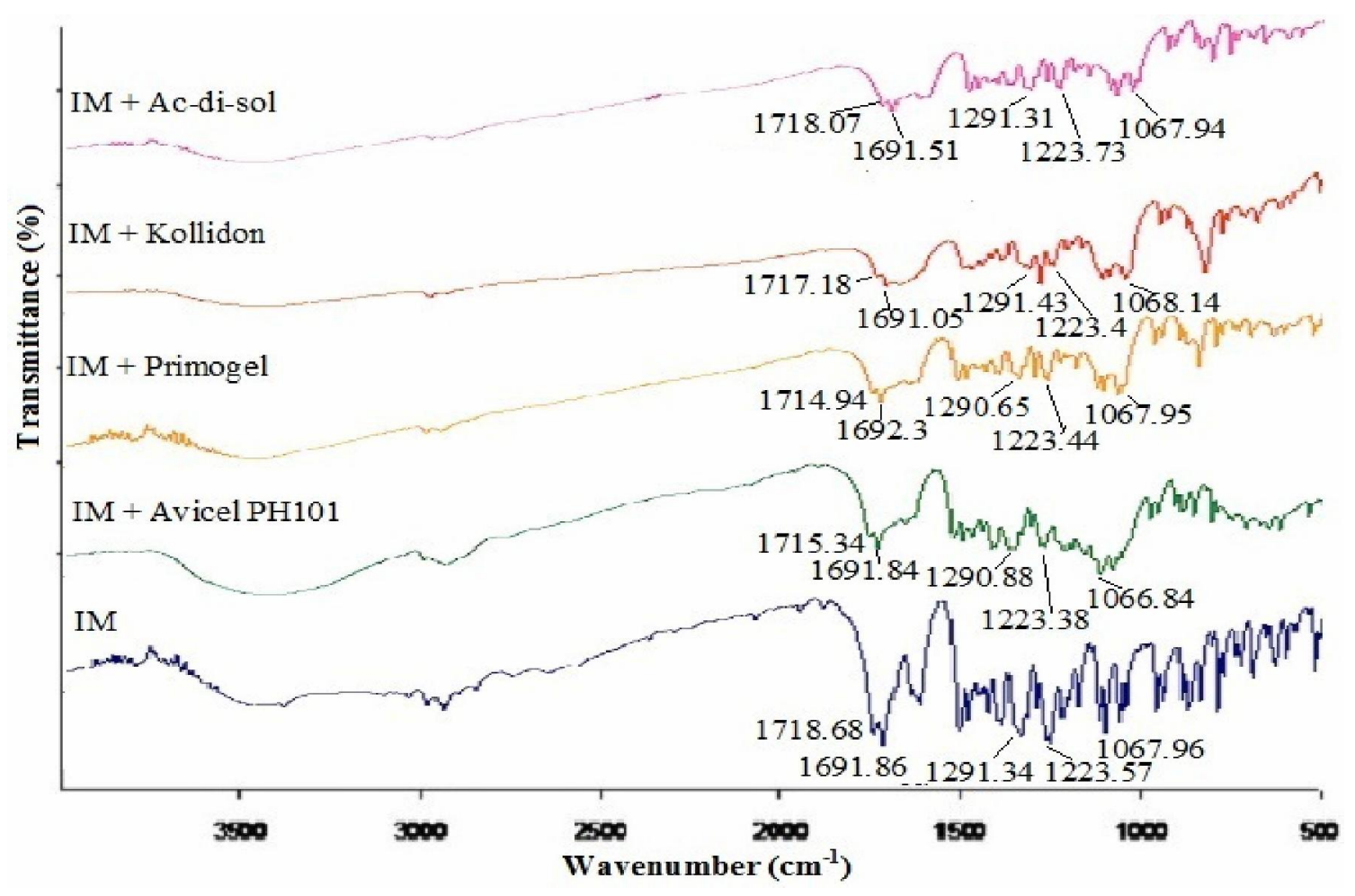

Figure 1. FT-IR spectra of pure drug and drug with Avicel, Primogel, Kollidon and Ac-di-sol.

Table II Physical Characteristics of powders of all the formulations of IM

\begin{tabular}{cccccc}
\hline $\begin{array}{c}\text { Formulation } \\
\text { code }\end{array}$ & $\begin{array}{c}\text { Bulk density } \\
\mathbf{( g / m L )}\end{array}$ & $\begin{array}{c}\text { Tapped } \\
\text { density }(\mathbf{g} / \mathbf{m L})\end{array}$ & $\begin{array}{c}\text { Carrs } \\
\text { index }\end{array}$ & $\begin{array}{c}\text { Angle of } \\
\text { repose }(\boldsymbol{\theta})\end{array}$ & $\begin{array}{c}\text { Hausner } \\
\text { ratio }\end{array}$ \\
\hline IF1 & $0.57 \pm 0.90$ & $0.84 \pm 0.78$ & $14.65 \pm 0.43$ & $28.94 \pm 0.74$ & $1.48 \pm 0.67$ \\
IF2 & $0.55 \pm 0.67$ & $0.85 \pm 0.65$ & $17.53 \pm 0.70$ & $27.94 \pm 0.36$ & $1.48 \pm 0.87$ \\
IF3 & $0.54 \pm 0.67$ & $0.84 \pm 0.89$ & $15.92 \pm 0.13$ & $26.14 \pm 0.65$ & $1.45 \pm 0.25$ \\
IF4 & $0.57 \pm 0.21$ & $0.85 \pm 0.56$ & $16.46 \pm 0.31$ & $29.94 \pm 0.73$ & $1.46 \pm 0.19$ \\
IF5 & $0.52 \pm 0.26$ & $0.85 \pm 0.16$ & $12.67 \pm 0.54$ & $27.94 \pm 0.37$ & $1.48 \pm 0.11$ \\
IF6 & $0.57 \pm 0.29$ & $0.84 \pm 0.76$ & $15.09 \pm 0.78$ & $26.14 \pm 0.62$ & $1.45 \pm 0.04$ \\
IF7 & $0.54 \pm 0.22$ & $0.84 \pm 0.55$ & $12.50 \pm 0.66$ & $25.14 \pm 0.40$ & $1.47 \pm 0.94$ \\
IF8 & $0.51 \pm 0.35$ & $0.84 \pm 0.52$ & $15.56 \pm 0.52$ & $26.19 \pm 0.56$ & $1.48 \pm 0.33$ \\
IF9 & $0.53 \pm 0.54$ & $0.85 \pm 0.68$ & $14.24 \pm 0.66$ & $24.94 \pm 0.24$ & $1.47 \pm 0.78$ \\
IF10 & $0.51 \pm 0.35$ & $0.81 \pm 0.52$ & $15.56 \pm 0.52$ & $27.39 \pm 0.56$ & $1.41 \pm 0.53$ \\
IF11 & $0.51 \pm 0.54$ & $0.88 \pm 0.68$ & $13.73 \pm 0.36$ & $25.54 \pm 0.27$ & $1.37 \pm 0.73$ \\
\hline
\end{tabular}

\section{Drug-excipient interaction study}

FT-IR spectra of pure IM, IM with Avicel, Primogel, Kollidon and Ac-di-sol were determined by $\mathrm{KBr}$ disc method and are presented in figure 1 . The characteristic peaks of IM were at $1067.96 \mathrm{~cm}^{-1}, 1223.57 \mathrm{~cm}^{-1}$,
$1291.34 \mathrm{~cm}^{-1}, \quad 1691.86 \mathrm{~cm}^{-1}$ and $1718.68 \mathrm{~cm}^{-1}$. There was no such significant shift in the position of major peaks in the above physical mixtures indicating that no chemical reaction or interaction between the drug and excipient took place. 
Dissolution Rate of Indomethacin

Table III. Comparison of physical parameters of all the of tablet formulations

\begin{tabular}{|c|c|c|c|c|c|c|c|c|c|c|}
\hline No & $\mathbf{A}$ & B & $\mathrm{C}$ & D & $\mathbf{E}$ & $\mathbf{F}$ & $\mathbf{G}$ & $\mathbf{H}$ & I & $\mathbf{J}$ \\
\hline IF1 & $348 \pm 0.45$ & $3.2 \pm 0.67$ & $5.84 \pm 0.77$ & 9.0 & 0.40 & 92 & $98.63 \pm 0.99$ & 58 & 16.9 & passes \\
\hline IF2 & $348 \pm 0.56$ & $3.1 \pm 0.86$ & $5.85 \pm 1.76$ & 9.0 & 0.54 & 69 & $97.53 \pm 0.59$ & 46 & 31.5 & Passes \\
\hline IF3 & $347 \pm 0.76$ & $3.1 \pm 0.65$ & $5.85 \pm 1.00$ & 9.0 & 0.66 & 56 & $97.33 \pm 0.78$ & 25 & 59.5 & Passes \\
\hline IF4 & $348 \pm 1.20$ & $3.2 \pm 0.34$ & $5.84 \pm 0.76$ & 9.0 & 0.40 & 83 & $98.44 \pm 0.43$ & 42 & 34.1 & Passes \\
\hline IF5 & $348 \pm 0.65$ & $3.0 \pm 0.56$ & $5.84 \pm 0.87$ & 9.0 & 0.17 & 68 & $98.16 \pm 1.07$ & 31 & 47.2 & Passes \\
\hline IF6 & $347 \pm 0.67$ & $3.1 \pm 0.73$ & $5.86 \pm 0.99$ & 9.0 & 0.55 & 51 & $99.72 \pm 0.98$ & 18 & 53.6 & Passes \\
\hline IF7 & $349 \pm 0.98$ & $3.0 \pm 1.10$ & $5.85 \pm 0.34$ & 9.0 & 0.20 & 78 & $96.47 \pm 0.65$ & 35 & 30.2 & Passes \\
\hline IF8 & $348 \pm 0.52$ & $3.1 \pm 0.23$ & $5.85 \pm 0.55$ & 9.0 & 0.18 & 58 & $97.65 \pm 0.32$ & 27 & 39.8 & Passes \\
\hline IF9 & $348 \pm 0.56$ & $3.0 \pm 0.41$ & $5.84 \pm 0.36$ & 9.0 & 0.22 & 44 & $98.21 \pm 0.61$ & 19 & 52.8 & Passes \\
\hline IF10 & $349 \pm 0.46$ & $3.2 \pm 0.45$ & $5.84 \pm 0.34$ & 9.0 & 0.24 & 56 & $99.43 \pm 0.78$ & 23 & 23.8 & Passes \\
\hline IF11 & $347 \pm 0.88$ & $3.3 \pm 1.0$ & $5.85 \pm 0.29$ & 9.0 & 0.28 & 38 & $98.87 \pm 0.65$ & 17 & 61.5 & Passes \\
\hline
\end{tabular}

$\mathbf{A}=$ Weight (mean $\pm \mathrm{SD}, \mathrm{mg}) \mathrm{n}=20 ; \mathbf{B}=$ Hardness (mean $\left.\pm \mathrm{SD}, \mathrm{kg} / \mathrm{cm}^{2}\right) \mathrm{n}=10 ; \mathbf{C}=$ Thickness $(\operatorname{mean} \pm \mathrm{SD}, \mathrm{mm})$ $\mathrm{n}=20 ; \mathbf{D}=$ Diameter (mean $\pm \mathrm{SD}, \mathrm{mm}) \mathrm{n}=20 ; \mathbf{E}=$ Diameter (mean $\pm \mathrm{SD}, \mathrm{mm}) \mathrm{n}=20 ; \mathbf{F}=$ Diameter $(\operatorname{mean} \pm \mathrm{SD}$, $\mathrm{mm})(\mathrm{n}=6) ; \mathbf{G}=$ Drug Content $(\%)(\mathrm{n}=10)$. ; $\mathbf{H}=$ Wetting time $(\mathrm{sec})(\mathrm{n}=6) ; \mathbf{I}=$ Water absorption ratio $(\mathrm{n}=6)$; $\mathbf{J}=$ Uniformity of dispersion $(\mathrm{n}=2)$.

Table IV. Comparison of physical parameters for optimized formulation IF11 before, during and after 3 months of stability study

\begin{tabular}{|c|c|c|c|c|}
\hline \multirow[b]{2}{*}{ Parameters } & \multirow{2}{*}{$\begin{array}{c}\text { IF11 } \\
\text { Initial }\end{array}$} & \multicolumn{3}{|c|}{$40^{\circ} \pm 2^{\circ} \mathrm{C} / 75 \pm 5 \% \mathrm{RH}$} \\
\hline & & $\begin{array}{l}\text { At the end } \\
\text { of } 1^{\text {st }} \text { month }\end{array}$ & $\begin{array}{l}\text { At the end of } \\
2^{\text {nd }} \text { month }\end{array}$ & $\begin{array}{l}\text { At the end } \\
\text { of } 3^{\text {rd }} \text { month }\end{array}$ \\
\hline Thickness (mm) & $5.85 \pm 0.29$ & $5.87 \pm 0.23$ & $5.88 \pm 0.31$ & $5.91 \pm 0.04$ \\
\hline Diameter (mm) & 9.0 & 9.0 & 9.07 & 9.1 \\
\hline Hardness $\left(\mathrm{kg} / \mathrm{cm}^{2}\right)$ & $3.3 \pm 1.0$ & $3.2 \pm 1.0$ & $3.3 \pm 1.0$ & $3.1 \pm 1.0$ \\
\hline Friability $(\%)$ & 0.28 & 0.28 & 0.29 & 0.30 \\
\hline Weight Variation (mg) & $347 \pm 0.88$ & $348 \pm 0.27$ & $348 \pm 0.09$ & $349 \pm 0.7$ \\
\hline Content Uniformity & $98.87 \pm 0.65$ & $98.27 \pm 0.12$ & $98.07 \pm 0.64$ & $97.77 \pm 0.75$ \\
\hline Disintegration time & $38 \mathrm{sec}$ & $35 \mathrm{sec}$ & $34 \mathrm{sec}$ & $34 \mathrm{sec}$ \\
\hline $\begin{array}{l}\text { In-Vitro release after } 60 \\
\text { minutes }\end{array}$ & $\begin{array}{l}99.54 \\
\pm 2.89\end{array}$ & --- & --- & $99.04 \pm 1.79$ \\
\hline
\end{tabular}

*Mean $\pm \mathrm{SD}, \mathrm{n}=10$ (hardness, friability and drug content studies), $\mathrm{n}=20$ (thickness, diameter and weight variation), $\mathrm{n}=6$ (disintegration and in-vitro drug release)

\section{Micromeretrics studies}

Powder mixtures of all the formulation were evaluated for various physical characteristics and the values were presented in table II. The values of bulk and tapped density are indicative of good packing character. Angle of repose gives qualitative and quantitative assessment of internal cohesive and frictional force. Values for angle of repose for all the formulations were ranged between $24.94 \pm 0.24$ and $29.94 \pm 0.73^{\circ}$, which indicated good flow properties (Martin et al., 2002). Further, Carr's index for all the formulation was found to be below $18 \%$. This indicates acceptable flow properties (Wells, 2002). Hausner ratio values for all the formulations were ranging from $1.37 \pm 0.73$ to $1.48 \pm 0.87$, indicating desirable flow properties. Hence, the prepared blends possessed good flow properties and these can be used to manufacture tablets by direct compression method. 
Rabinarayan Parhi

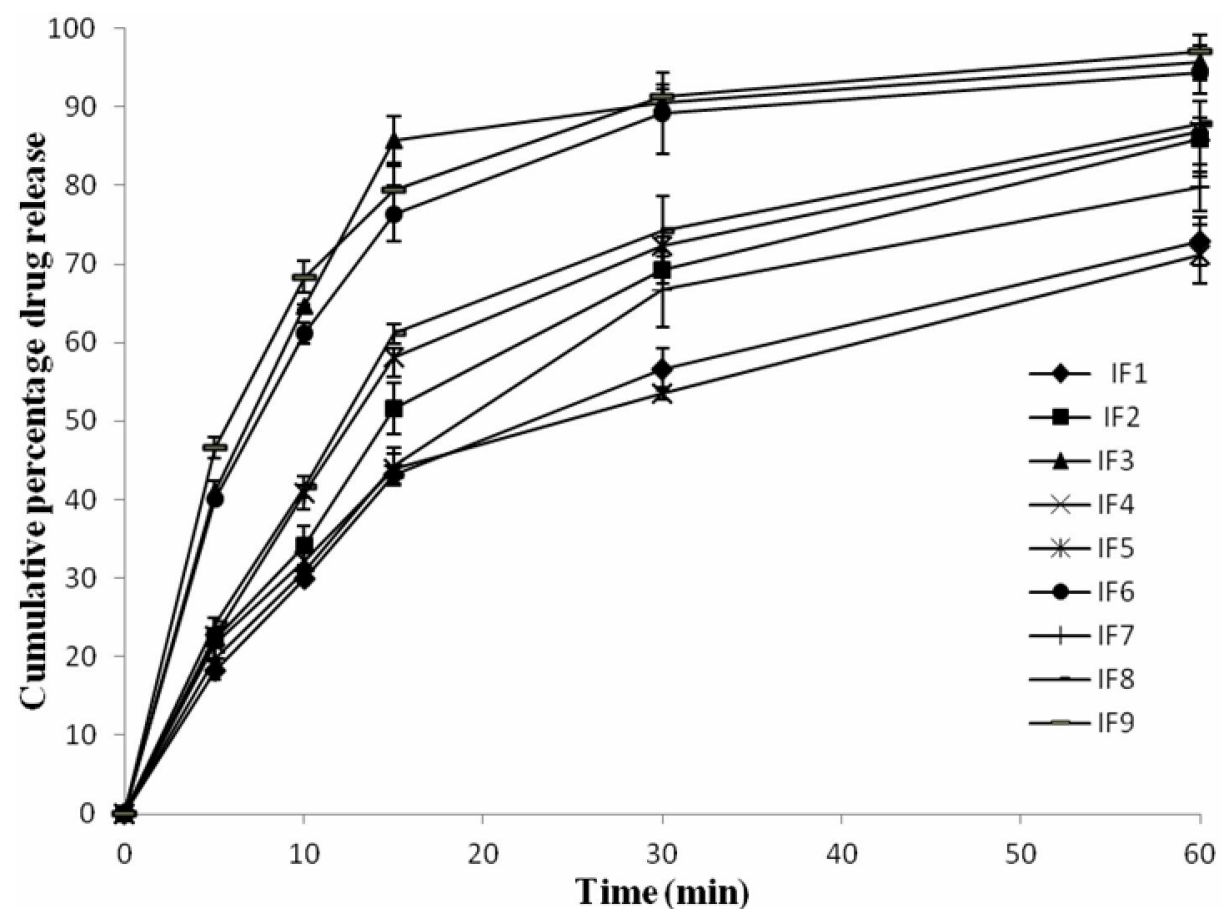

Figure 2. Dissolution profile of formulations from IF1 to IF9 (mean $\pm S D, n=6)$

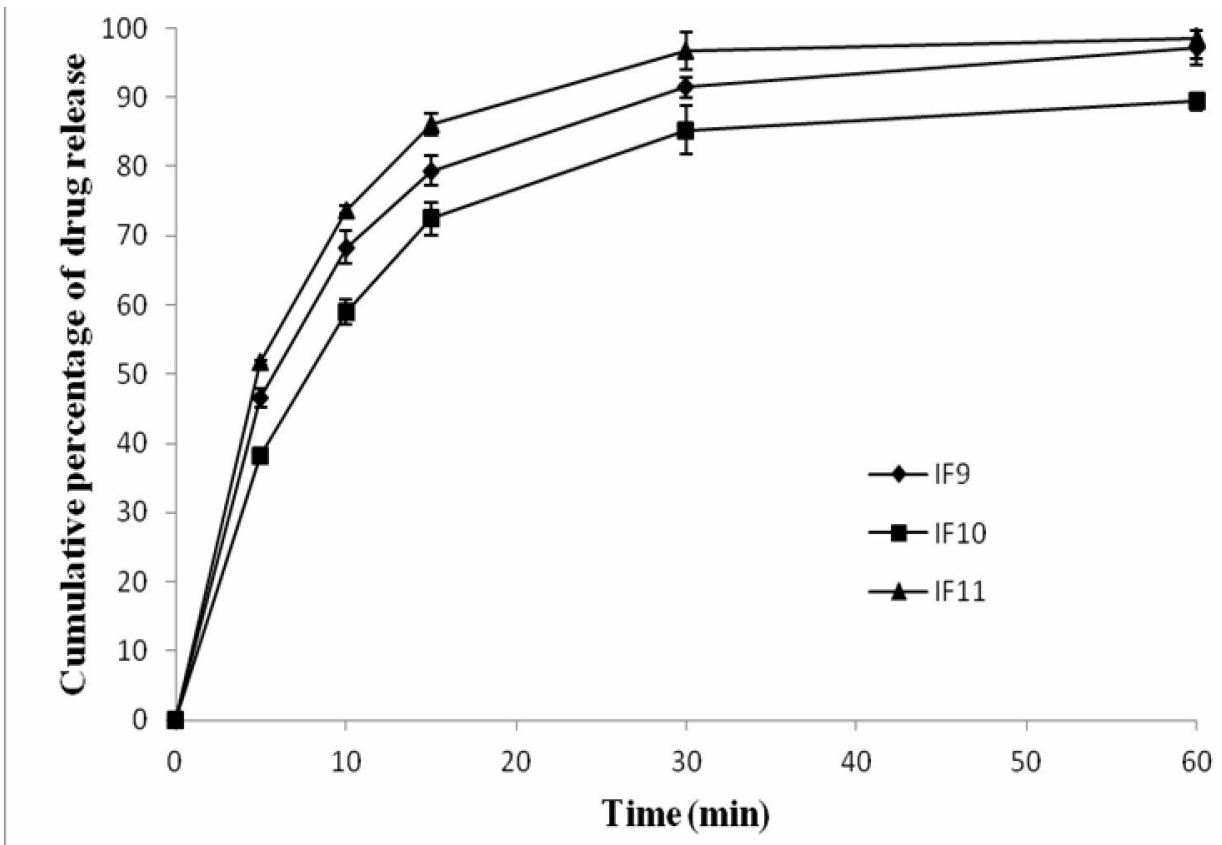

Figure 3. Dissolution profile of formulations from IF9 to IF11 (mean \pm SD, $n=6$ ) 
Dissolution Rate of Indomethacin

\section{Physical parameters of tablets}

All the tablet formulations were processed under similar condition to avoid any type of variation in physical tests and the results are given in the table III. The average percentages of weight variation for all the tablet formulations were within the acceptable limit. All the formulation shows uniform diameter and the percentage of thickness deviations were within the limit. Hardness of all the batches of tablets was above $3 \mathrm{~kg} / \mathrm{cm} 2$. Hardness is not an absolute indicator of tablet strength. So, friability was measured by taking 10 tablets in Roche friabilator from each batch and the values demonstrates that the friability of all the batches were within the official limit $(\leq 1 \%)$ (Swamy etal., 2011, United States Pharmacopeia, 2009). The hardness and friability values indicate good mechanical strength to withstand handling and transportation. The drug content uniformity of FDTs was between $96.4 \pm 0.65$ and $99.43 \pm 0.78$.

The wetting and disintegration time, for formulations contaning Primogel as superdisintegrants, decreases with increase in superdisintegrant amount per tablet from 4mg in IF1 to $12 \mathrm{mg}$ in IF3. Same trend was also observed in case of formulations containg Kollidon and Acdi-sol as super-disintegrants. This was attributed to the fact that more the amount of superdisintegrant higher is the water absorption and swelling, resulting in rapid wetting and disintegration of tablets. The disintegration time for all the batches of tablets were well below the accepted official limit of $3 \mathrm{~min}$. The least values for wetting time $(17 \mathrm{~s})$ and disintegration time (38s) were shown by formulation IF11. This may be due to the combination of superdisintegration and efferevescence approaches. Uniformity of dispersion is performrd to predict how well the tablet is going to disintegrats in mouth without any particulate matter above size $710 \mathrm{~nm}$. All the dveloped tablet batches passed the test.

\section{In vitro dissolution studies}

In-vitro dissolution studies of all the FDT formulations were carried out for $60 \mathrm{~min}$ in USP dissolution apparatus II containing phosphate buffer $\mathrm{pH} \quad 6.8$ and data were represented in Figure $2 \& 3$. In addition to two approaches namely super-disintegration and effervescence, a combination approach containing both the ingredients was used. The order of increased drug dissolution using above approaches was as follows; combination > super-disintegration $>$ effervescence.

In case of super-disintegration, the cumulative percentage of drug release for formulation IF1-IF9 increases with the increase in super-disintegrants amount from $4 \mathrm{mg}$ to 12 mg per tablet. It is based on the fact that higher the concentration of super-disintegrants more rapid is the disintegration followed by drug release. Among different super-disintegrants used Ac-di-sol shown highest percentage of drug release after $60 \mathrm{~min}$ of dissolution at same concentration followed by Primogel and Kollidon, which is in accordance with Gryczke et al., 2011. This result was attributed to different disintegration mechanisms of selected super-disintegrants. Primogel and Kollidon act by swelling by absorbing water leading to separation of tablet into particles. In case of Ac-di-sol the mechanism of action is wicking via capillary action followed by disruption of the inter-particular matrix bonds resulting in the tablet disintegration (Kottke et al., Be et al., 1999). Formulation IF9 containing $12 \mathrm{mg}$ of Ac-di-sol released highest cumulative percentage of drug $(97.13 \pm 2.09 \%)$ at $60 \mathrm{~min}$.

For formulation based on effervescence principle, provides a cumulative percentage of drug release of $89.41 \pm 1.21 \%$ after $1 \mathrm{hr}$, which was in between the formulations (IF2, IF5 and IF8) containing $8 \mathrm{mg}$ per tablet and formulation (IF3, IF6 and IF9) having $12 \mathrm{mg}$ per tablet of different super-disintegrants. Combination of two approaches resulted in increase in dissolution rate. Among all the ODT formulations, IF11 released highest amount of drug release $(98.54 \pm 2.9 \%$ ) after 60 $\mathrm{min}$. This could be due to the synergistic effect of Ac-di-sol and $\mathrm{CO}_{2}$ released as soon as the tablet came in contact with water. This released $\mathrm{CO}_{2}$ accelerated the disintegration, which was in accordance with wetting and disintegration time (Table 3).

\section{Statistical analysis}

One-way ANOVA data showed that there were significant differences of in vitro drug release $(\mathrm{P}<0.05$ level), when IF9 compared with batches from IF1 to IF8, between the batches 
except IF9-IF3 and IF9-IF6. Among IF9-IF11, the significant differences observed between IF9 with IF10 and IF10 with IF11. The former results could be due to different types of superdisintegration and their concentrations and the different approaches may be reason in the later case.

\section{Stability studies}

The evaluated physical parameters of formulation IF11 before and at the end of each months and in vitro drug release for optimized formulation IF11 before and after 3 months of stability study were presented in Table 4. From the mentioned data it was evident that there was no significant change in thickness, diameter, weight variation, hardness, content uniformity and in-vitro dissolution profile of optimized formulation.

\section{CONCLUSIONS}

Fast dissolving tablets of IM were prepared in the present research work to increase its solubility and followed by the bioavailability. Super-disintegration (IF1-IF9), effervescence (IF10) and combination of the both approaches (IF11) were used to develop FDT. It was observed that, among all the super-disintegrants used, formulations having Ac-di-sol showed highest amount of drug release at same concentration as compared to Primogel and Kollidon. The formulation IF10 released less amount of drug when compared to formulation containing super-disintegrants at higher concentration at $60 \mathrm{~min}$. Out of all the eleven formulations, IF11 showed highest amount $(98.54 \pm 2.89)$ of drug release at the end of $1 \mathrm{hr}$. There were no significant changes in physical and in vitro data obtained after 3 months of stability studies at accelerated condition. In vivo studies required to further ascertain its commercial viability.

\section{REFERENCES}

Aeinleng, N., Songkro, S., Noipha, K., Srichana, T., 2012, Physicochemical Performances of Indomethacin in Cholesteryl Cetyl Carbonate Liquid Crystal as a Transdermal Dosage, AAPS PharmSciTech, 13, 513-521.

Banker, GS., Anderson, N. R., 1987, Tablets, In: Lachman, L., Lieberman, H. A.,
Kanig, J. L. (Eds.), The Theory and Practice of Industrial Pharmacy, 3rd ed. Varghese Publishing House, Mumbai, pp. 327.

Barnhart, S. D., Sloboda, M. S., 2007, Dissolvable films the future of dissolvable films, Drug Dev. Tech., 1, 3435.

Bhalla, N., Deep, A., Goswami, M., 2012, An overview on various approaches oral controlled drug delivery system via gastro-retention drug delivery system, Int. Res. J. Pharm., 3, 128-33.

Bi, Y. X., Sunada, H., Yonezawa, Y., Danjo, K., 1999, Evaluation of rapidly disintegrating tablets prepared by a direct compression method, Drug Dev. Ind. Pharm., 25, 571581.

Cooper, J., Gunn, C., 1986, Powder flow and compaction. In: Carter, S. J. (Ed.), Tutorial Pharmacy, CBS Publishers and Distributors, New Delhi, India, pp. 211233.

Douroumis, D., 2007, Practical approaches of taste masking technologies in oral solid forms, Expert Opin. Drug Deliv., 4, 417426.

Elkhodairy, K. A., Hassan, M. A., Afifi, S.A., 2013, Formulation and optimization of orodispersible tablets of flutamide. Saudi Pharm. J. Article in Press,

Ghosh, T. K., Jasti, B. R., (Ed.), 2005, Theory and Practice of Contemporary Pharmaceutics, CRC press, pp. 282-367, 150-155.

Goto T., Tanidab, N., 2004, Pharmaceutical design of a novel colon-targeted delivery system using two-layer-coated tablets of three different pharmaceutical formulations, supported by clinical evidence in humans, J. Control. Release, 97, $31-42$.

Gryczke, A., Schminke, S., Maniruzzaman, M., Beck, J., Douroumis, D., 2011, Development and evaluation of orally disintegrating tablets (ODTs) containing Ibuprofen granules prepared by hot melt extrusion, Colloids and Surfaces B: Biointerfaces, 86, 275-284.

Guidance for Industry: Orally Disintegrating Tablets, Center for Drug Evaluation and Research (CDER) US FDA, Dec. 2008. 
Habibh, W., Khankarik, R., Hontz, J., 2000, Fast-dissolve drug delivery system, Crit. Rev. Ther. Drug Carrier Syst., 17, 61-72.

Indian Pharmacopeia, Vol. II, 2010, The Government of India, Ministry of Health \& Family welfare. The Indian Pharmacopeial commission, Ghaziabad, India, pp. 752-753.

Kottke, M. K., Rudnic, E. M., 2002, In: Rhodes CT., Banker GS., (Eds.), Modern Pharmaceutics, 4th ed, Mercel Dekker, INC. New York. Basel, PP. 299-300.

Krishnaiah, Y. S. R., Karthikeyan, R. S., Satyanarayana, V., 2002, A three-layer guar gum matrix tablet for oral controlled delivery of highly soluble metoprolol tartrate, Int. J. Pharm., 241, 353-366.

Kulmacz, RJ., 1989, Topography of prostaglandin $\mathrm{H}$ synthase. Antiinflammatory agents and the proteasesensitive arginine 253 region, J. Biol. Chem., 264, 14136-14144.

Martin, A., Bustamante, P., Chun, A., 2002, Micromeritics, In: Physical PharmacyPhysical Chemical Principles in the Pharmacentical Sciences, $4^{\text {th }}$ ed., Lippincott Williams and Wilkins, Baltimore, pp. 446-448

Peppas, NA., Buri, PA., 1985, Surface, interfacial and molecular aspects of polymer bioadhesion on soft tissues, $J$. Control. Release, 2, 257-275.

Prabhu, P., Malli, R., Koland, M., Vijaynarayana, K., et al., 2011, Formulation and evaluation of fast dissolving films of levocitirizine dihydrochloride, Int. J. Pharm. Invest., 1, 99-104.

Saurabh, R., Malviya, R., Sharma, PK., 2011, Trends in buccal film: formulation characterization, recent studies and patents, Eur. J. Appl. Sci., 3, 93-101.

Shen, TY., 1982, The discovery of indomethacin and the proliferation of NSAIDs Seminars in Arthritis and Rheumatism, 12, 89-93.

Swamy, PV., Kinagi, M. B., Biradar, S. S., Gada, S. N., Shilpa, H., 2011, Formulation Design and Evaluation of Bilayer Buccal Tablets of Granisetron Hydrochloride, Ind. J. Pharm. Edu. Res., 45, 242-247.

Szakonyi, G., Zelkó, R., 2013, Prediction of oral disintegration time of fast disintegrating tablets using texture analyzer and computational optimization, Int. J. Pharm., 448, 346353.

Tejvir, K., Bhawandeep, G., Sandeep, K., Gupta, G. D., 2011, Mouth dissolving tablets: a novel app to drug delivery, Int. J. Cur. Pharm. Res., 3, 1-7.

Tritthart, W., Piskering, MA., 2001, Solid, rapidly disintegrating cetrizine formulations. US Patent, 6, 245, 353.

United States Pharmacopeia 32/NF27, Volume 1, 2009, The Official Compendia of Standards. Asian Rockville, M.D. (Ed.), United States Pharmacopoeia Convention Inc, pp. 725-726.

Wells, J., 2002, Pharmaceutical preformulation: the physicochemical properties of drug substances, In: Aulton, M. E. (Ed.), 2nd ed, Pharmaceutics: The Science of Dosage Form Design, Churchill Livingstone, London, England, pp. 133-134.

Wu, CY., Seville, JPK., 2009, A comparative study of compaction properties of binary and bilayer tablets, Powder Tech., 189, 285-294. 